\title{
The state of kidney transplantation in South Africa
}

\author{
M R Moosa, MB ChB, FCP, MD, FRCP \\ Division of Nephrology, Department of Medicine, Faculty of Medicine and Health Sciences, Stellenbosch University, Cape Town, South Africa; \\ and Renal Unit, Tygerberg Hospital, Cape Town, South Africa
}

Corresponding author: M R Moosa (rmm@sun.ac.za)

\begin{abstract}
Background. Kidney transplantation has been performed in South Africa (SA) since 1966. Transplants were initially limited to public hospitals, and the entry of the private sector heralded a new era in organ transplantation.

Objectives. To document kidney transplantation in SA and compare numbers, rates, trends and sources of kidneys transplanted in the public and private sectors in SA over 25 years.

Methods. National kidney transplant data collected between 1991 and 2015 by the Organ Donor Foundation of South Africa were analysed. The total number of kidneys transplanted in the country was counted and rates were calculated. The numbers and rates in the private and public sectors were compared. The source of donor kidneys and sites where transplants were performed were documented.

Results. Over the 25-year period under review, 7191 kidney transplants were performed in SA. The overall kidney transplant rate was 6.4 per million population (pmp), averaging $4.8 \mathrm{pmp}$ in the public sector and $15.2 \mathrm{pmp}$ in the private sector; $58.3 \%$ of the donor kidneys were derived from deceased donors. Cape Town and Johannesburg hospitals performed $75 \%$ of the country's kidney transplants.

Conclusions. The overall transplant rate in SA is declining, especially in the public sector. Most kidney transplants in the country were performed in the public sector, and deceased-donor transplants predominated. Discrepancies exist in the allocation of kidneys. Recommendations are made on how the situation may be improved.
\end{abstract}

S Afr Med J 2019;109(4):235-240. DOI:10.7196/SAMJ.2019.v109i4.13548

The first kidney transplant on the African continent was performed in Johannesburg, South Africa (SA), by Thomas Starzl and Bert Myburgh in $1966,{ }^{[1]}$ preceding the world's first heart transplant performed by Christiaan Barnard in Cape Town in 1967. ${ }^{[2]}$ Transplant activity in SA remains lower than that achieved by other countries with comparable economic capacity. ${ }^{[3]}$ Currently there are seven centres each in the public and private sectors offering kidney transplantation, distributed between five cities and four provinces. These transplant centres serve the 30 dialysis units in the public sector and the 228 units in the private sector. ${ }^{[4]}$ Kidney disease is increasing in SA and has become one of the leading causes of mortality, accounting for a staggering 1000 deaths per million population (pmp). ${ }^{[5]}$ The challenge of coping with this situation is starkly illustrated in a recent report from a renal unit in Western Cape Province that currently accepts only $25 \%$ of patients with endstage kidney disease (ESKD) referred for treatment, down from $50 \%$ a decade ago. ${ }^{[6,7]}$

The growing demand for renal replacement treatment places enormous pressure on already overburdened dialysis units around the country; the units in the public sector are particularly stressed. ${ }^{[8,9]}$ SA has a two-tiered health system: a private health system is available to the $16 \%$ of the population that is able to afford medical insurance, and benefits from world-class medical care, while the remaining majority $(84 \%)$ of uninsured individuals are served by state facilities that are generally under-staffed and under-resourced. ${ }^{[10]}$ The marked discrepancy in healthcare is poignantly reflected in the access to renal replacement treatment: in 2015 the treatment rate in the public sector was $72 \mathrm{pmp}$ compared with $799 \mathrm{pmp}$ in the private sector. ${ }^{[4]}$ The higher treatment rate in the private sector is because dialysis is a 'prescribed minimum benefit' introduced in SA in 1998 and requiring health insurers, among other obligations, to guarantee treatment for 25 chronic diseases, including chronic renal failure, regardless of the benefit option selected by the patient. To cope with the demand for renal replacement treatment, the number of private dialysis units increased dramatically from 5 in 1994 to 228 in 2015; during the same period, the number of units in the public sector merely increased from 26 to $30 .{ }^{[4]}$ Haemodialysis was the predominant form of renal replacement in both sectors, with $46 \%$ of patients in the public sector and $85 \%$ in the private sector receiving this treatment. Only $25 \%$ of renal replacement patients in the public sector and a mere $8 \%$ in the private sector were kidney transplant recipients. ${ }^{[4]}$

\section{Objectives}

With kidney transplantation recognised as the most effective treatment for ESKD, both clinically and economically, the author interrogated the pattern of kidney transplantation in SA in the hope of assisting clinicians and health authorities in both the public and private sectors to develop strategies to improve kidney transplantation rates in SA. The primary objective of this study was to establish the pattern of kidney transplantation in ESKD patients in SA during the period 1991 - 2015, and determine any differences in rates and donor sources of kidney transplants performed in the public and private sectors.

\section{Methods}

The Organ Donor Foundation of South Africa, a non-profit and public benefit organisation established in 1988, has collected national data on kidney transplantation from all transplant units in SA since 1991, in both the public and the private sectors, and made the data up to 2015 available for study. For the purposes of this study, public sector hospitals were those funded by the provincial governments while private sector hospitals were owned and/or operated by private companies. The distinction pertinently does not refer to the 
medical staff, some of whom operated across the two sectors. The data collected by the Foundation were provided voluntarily by the transplant units, were generally limited to the number and type of transplants performed at the various centres, and were collected annually. All data were captured on an Excel spreadsheet, version 2013 (Microsoft, USA). The number of kidney transplants performed since 1991 was counted and rates of transplant were calculated using mid-year population data supplied by Statistics South Africa. The data were rendered graphically, including trend lines.

Data made available by the Organ Donor Foundation contained summary information with no personal identifying information. The study was approved by the Stellenbosch University Human Research Ethics Committee (ref. no. N16/01/001). As the data collected were retrospective and anonymous, a waiver of informed consent was granted.

\section{Results}

During the 25-year period under review, a total of 7191 kidney transplants were performed in SA. The trend has been towards a decline in total number of kidney transplants in the country in this period, although a spike in the total number of transplants occurred between 2001 and 2003 because of a sharp increase in the number of transplants in the private sector (Fig. 1). Of the total number of kidney transplants, 4302 (59.9\%) were performed in the public sector. Although there was a decline in the overall number of kidney transplants in the country, there was a difference between the two sectors, with a steady increase in the private sector but a declining number of transplants in the public sector. The number of kidneys transplanted in the private sector transiently exceeded that in the public sector in 2002 and 2003 and consistently exceeded it after 2009 (Fig. 1). However, in terms of the kidney transplant rate, the private sector overtook the public sector as early as 1995 (Fig. 2). While the overall kidney transplant rate and the rate in the public sector are declining, the rate in the private sector has increased and at worst has plateaued. In 2012, the rate of transplantation in the private sector was more than seven-fold that in the public sector, but averaged 2.7fold over the study period (Fig. 2).

Over the past 25 years, 2990 transplants (41.6\%) were performed in Cape Town (Western Cape) and 2455 (34.1\%) in Johannesburg (Gauteng Province), the two cities accounting for over $75 \%$ of all transplants in SA between them. However, Gauteng, which includes transplant centres in the cities of Johannesburg and Pretoria, performed the largest number of transplants during this period, totalling 3088 . The transplant rates in the various provinces are shown in Table 1.

National data on the donor source of the kidneys used in transplantation (deceased v. living donor) have been available since 2000, and of the 4545 kidney transplants performed during this period until 2015, 2641 (58.3\%) were from deceased donors (Fig. 3). On aggregate deceased-donor transplants exceeded living-donor transplants each year, apart from 2009 (Fig. 3); however, projection suggests that living-donor transplants may overtake deceased-donor transplants within a few years if the current trend continues. The decline in deceased-donor kidney transplants in the public sector has been particularly severe (Fig. 4). The main source of organs in both larger centres since 2000 has been deceased donors, amounting to 1112 kidneys (58.6\%) transplanted in the Western Cape and 1304 (64.4\%) in Gauteng. In this 16-year period in the Western Cape, $77.8 \%$ of transplants were in public sector patients compared

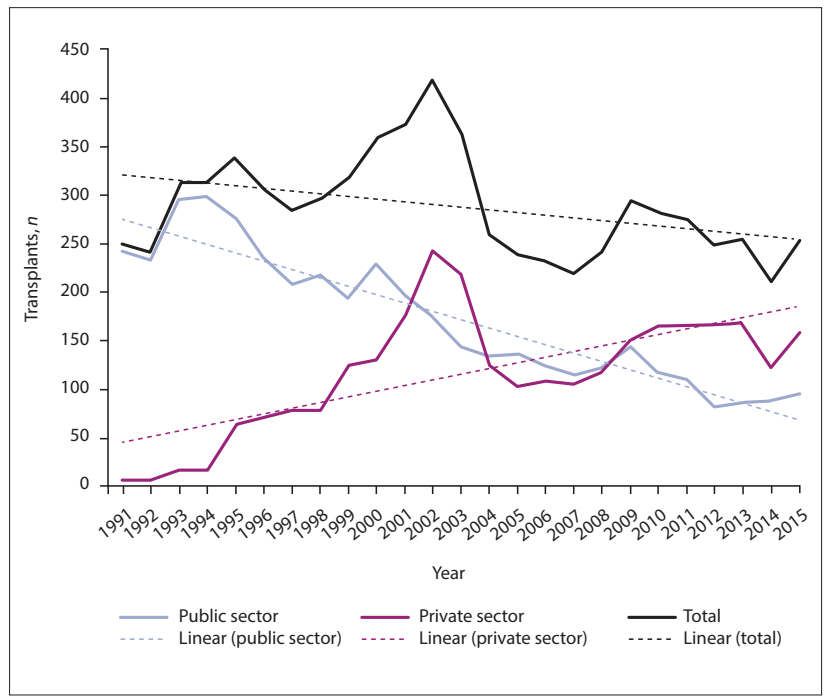

Fig. 1. Number of kidney transplants performed in South Africa, per sector and in total, 1991 -2015. Trend lines are shown.

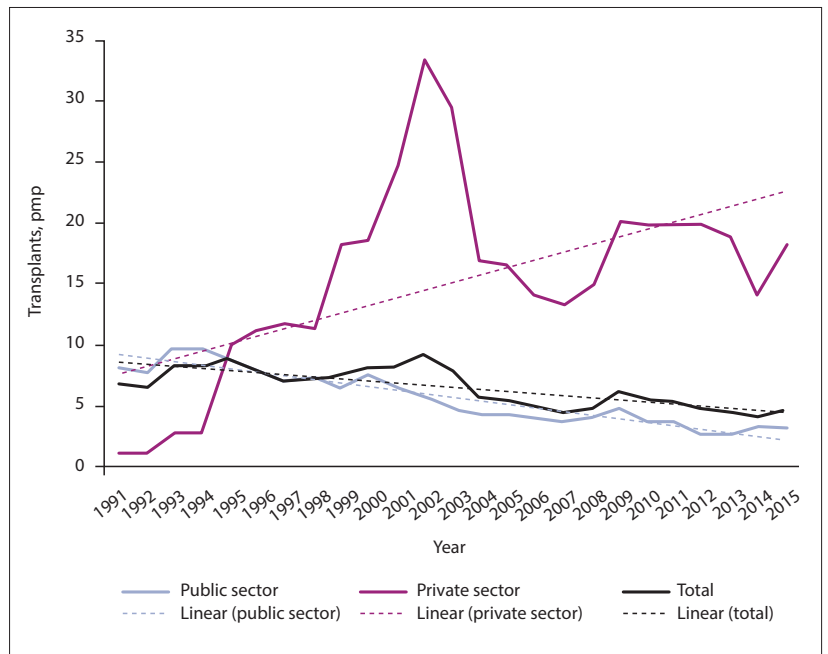

Fig. 2. Rate of kidney transplantation in South Africa (pmp), per sector, 1991 - 2015. The mean transplant rate in the private sector was $15.2 \mathrm{pmp}$ and in the public sector $4.8 \mathrm{pmp}$. Trend lines are shown. (pmp = per million population.)

Table 1. Total number of kidney transplants performed in different regions of South Africa in the public and private sectors, 1991 - 2015

\begin{tabular}{|c|c|c|c|c|c|}
\hline Transplant region & Public, $n(\%)$ & Private, $n(\%)$ & Total, $N$ & Population (million)* & Rate pmp \\
\hline Gauteng & $1528(49.5)$ & $1560(50.5)$ & 3088 & 9.5 & 13.1 \\
\hline Western Cape & $2346(78.5)$ & $644(21.5)$ & 2990 & 4.7 & 25.2 \\
\hline KwaZulu-Natal & $339(34,2)$ & $653(65.8)$ & 992 & 9.7 & 4.1 \\
\hline Free State & $89(73.6)$ & $32(26.4)$ & 121 & 2.8 & 1.7 \\
\hline
\end{tabular}




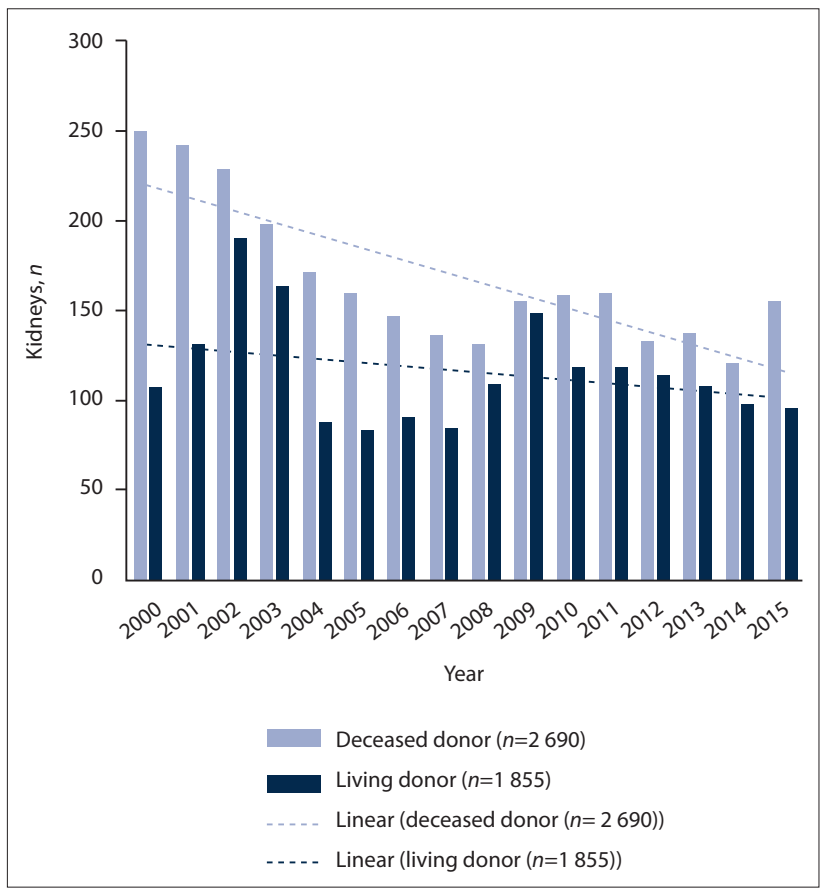

Fig. 3. Number of kidneys transplanted from deceased and living donors in South Africa, 2000 - 2015. Trend lines are shown.

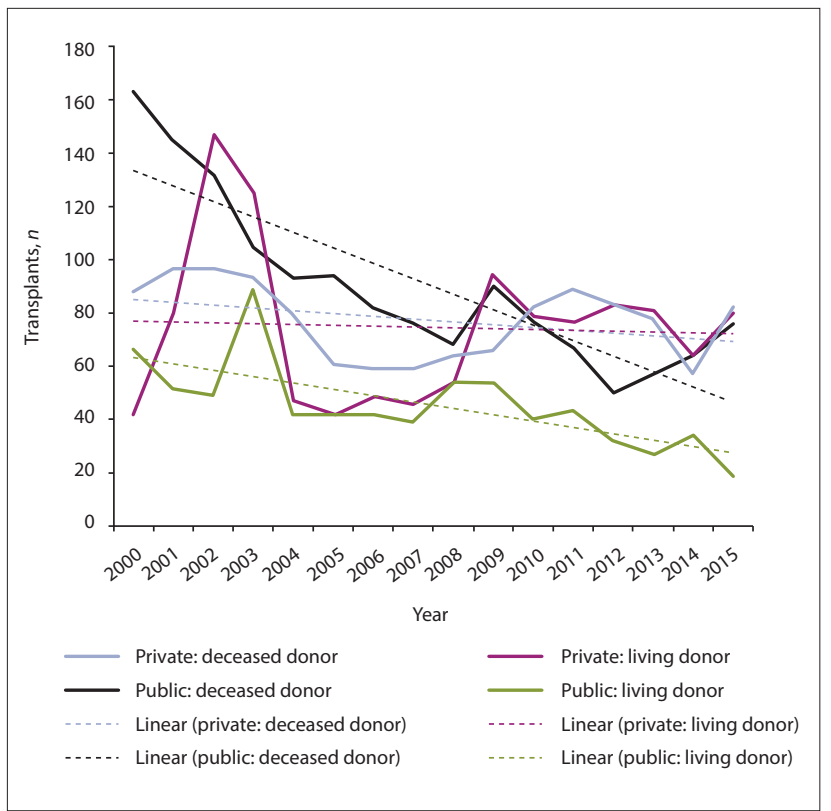

Fig. 4. Transplant activity in the public and private sectors, and source of kidneys. Trend lines are shown.

with $36.6 \%$ in Gauteng, where private sector patients were the main beneficiaries (Fig. 5). In the Western Cape, most donors (67.4\%) were derived from the public sector while in Gauteng most donors (63.4\%) were from the private sector.

The number of transplant centres in SA has increased over the years, with growth occurring almost exclusively in the private sector. In 1991 the only private hospital to report kidney transplants was St Augustine's Private Hospital in Durban (part of what is now the Netcare Group). All other kidney transplants were performed in public hospitals, with two centres each in Cape Town, Pretoria and Johannesburg and one each in Durban and Bloemfontein.

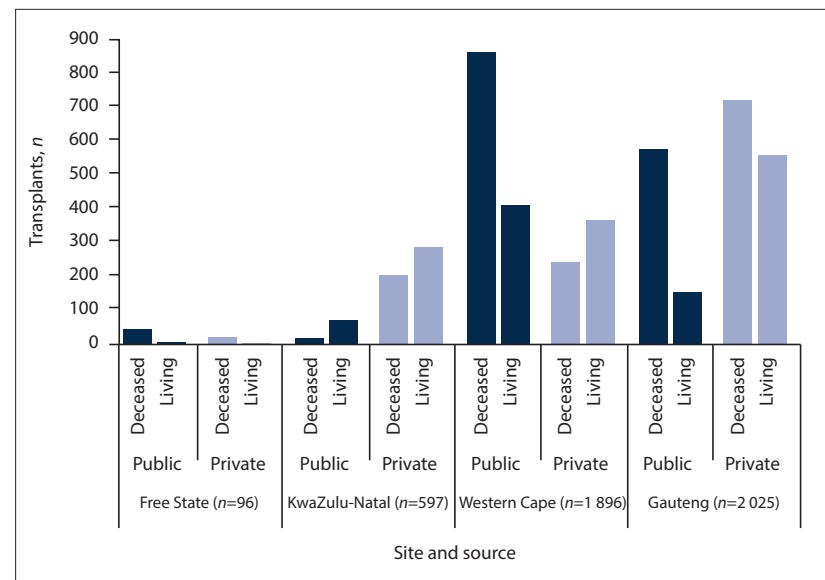

Fig. 5. Source of kidneys and number of transplants in the different transplant regions, 2000 - 2015. The public sector is depicted in dark blue and the private sector in light blue.

Baragwanath Hospital (now Chris Hani Baragwanath Academic Hospital), one of the two transplant centres in Johannesburg, reported its last kidney transplant in 1994; all subsequent public sector transplants have been done at Johannesburg General Hospital (now Charlotte Maxeke Academic Hospital). In 1995 the first private kidney transplants were reported by hospitals in the Clinic Holdings Group (now part of the Netcare Group) in Cape Town, Johannesburg and Pretoria, and these hospitals continue to provide a transplant service. Life Healthcare (previously Afrox Holdings) reported sporadic kidney transplant activity in Entabeni and its Flora Clinic in Johannesburg in 1994 - 2004. In Durban in 2003 public sector kidney transplant reporting shifted to Inkosi Albert Luthuli Central Hospital from Addington Hospital, where transplants had previously been performed. Wits Donald Gordon Medical Centre, the first private teaching hospital in SA, reported its first kidney transplants in 2004 and has become a very significant role player in organ transplantation in SA. In 2008 the Netcare Group reported the first private kidney transplants in the Free State at Universitas Private Hospital, and in 2011 the UCT Private Hospital in the Netcare Group became operative, expanding private sector transplant availability in the Western Cape.

Allocation of organs has changed over the years, but currently major centres allocate organs on a points system, with patient time waitlisted as the main determinant and including age, previous sensitisation and comorbid issues. ${ }^{[11]}$ In Cape Town, the centre providing a donor is allocated a kidney and the remaining kidney is allocated to the combined public-private patient pool. In Johannesburg, kidneys are allocated one each to the private and public sectors, irrespective of their source.

\section{Discussion}

SA has a proud heritage of organ transplantation. Transplants were initially exclusively performed in the public sector, but over the past quarter century there has been a healthy increase in transplant activity in the private sector. The entry into this field of the private sector, with more resources and greater efficiencies, was a welcome addition that should have enhanced the rate of transplantation in the country. However, this was never realised over the years; the exception was the spike in 2001 - 2003 that was a result of alleged illicit transplant activity in the private sector. ${ }^{[9]}$ The source of kidneys in SA is a fair balance between deceased and living donors, with the former still predominating. SA has a road traffic death rate of 251 
pmp, which suggests that there should potentially be sufficient organs to meet the needs of the country; ${ }^{[12]}$ the reasons for the decline in kidney transplants despite this are multiple and include structural and policy issues, and attitudinal challenges.

Resource issues pose obstacles but are amenable to strategic intervention, and include logistic constraints including a paucity of transplant co-ordinators, limited access to operating theatres, scarce intensive care beds ${ }^{[13]}$ and lack of skilled clinical and nursing personnel. ${ }^{\left[{ }^{[]}\right.}$The new SA government prioritised primary healthcare in 1994 when it assumed power, despite the growing burden of diseases such as chronic kidney disease. ${ }^{[14]}$ What has been encouraging, however, was a recent national summit on chronic kidney disease hosted by the National Department of Health, suggesting a softening of political attitude to the challenges of chronic kidney disease. ${ }^{[8]}$ Changing attitudes and perceptions are more challenging: public attitudes towards organ donation remain consistently supportive of it and contrast with the reality of the declining transplant rates reported. ${ }^{[15,16]}$ Although these studies were reported prior to the international organ trafficking scandal in which SA became embroiled, ${ }^{[11,17,18]}$ the current study shows that the decline in the transplant rate preceded these alleged illicit activities, although their impact on public opinion has never been studied. Since then, SA has become a signatory to the Istanbul Declaration ${ }^{[19]}$ and all forms of commerce in organ transplantation are deemed illegal. In response to the scandal, a Ministerial Advisory Committee on Organ Transplantation consisting of experienced clinicians was appointed and now screens all potential living donor kidney transplants (except genetically related donors). SA is ethnically, culturally, socially and religiously a very diverse nation, and these differences often act as barriers to organ donation but are not insurmountable, as most religions and cultures support transplantation. ${ }^{[15]}$

In evaluating other strategies to improve organ donation (summarised in Table 2), several key factors are important. Perhaps the most important is the political will of the national government to support transplant programmes, as demonstrated by the highly successful Spanish and Croatian models that have in common a centralised approach with health authorities and governments playing key roles, appointment of a specialised hospital team dedicated to organ donation, incentives to donor hospitals by reimbursement and, importantly, intense public awareness drives. The introduction of deemed consent policies was considered less critical, an important consideration in the culturally and ethnically diverse population of SA. ${ }^{[20-22]}$ SA is moving towards universal health coverage in an effort to provide more equitable access to healthcare; the White Paper lists dialysis and transplantation as services that will be offered, and this may provide an opportunity for protagonists to influence policy to facilitate organ donation and promote kidney transplantation. ${ }^{[23]}$ The affordability of the policy is uncertain, however, and it may be decades before universal access is fully realised. ${ }^{[24]}$

Incentivising living unrelated organ donation was highly successful in Iran, where the state not only sanctioned but co-ordinated 'rewarded gifting. ${ }^{[25]}$ In this model, initiated in 1997, the donor received a substantial financial reward from the state as well as medical insurance for a year. While this unique programme eliminated the waiting list for kidneys, it does have its critics, who warn against the possible exploitation of poorer vendors. ${ }^{[26]}$ Israel successfully introduced an alternative incentive model, whereby the state rewarded signed-up donors by prioritising them and their first-degree relatives should they need an organ. The relatives of deceased donors were also given priority. ${ }^{[27]}$ In addition, living altruistic donation was promoted, largely by removing disincentives. These policy changes resulted in dramatic improvements in transplant activity. ${ }^{[28]}$

Finally, changing attitudes is crucial to improve organ donation. Among South Africans, the level of awareness is high and $70 \%$ of interviewees recently indicated willingness to donate after death. ${ }^{[16]}$ However, this willingness to donate has not translated into real donations: $82 \%$ of families refused when actually approached for postmortem donations. ${ }^{[29]}$ Another important barrier to donation is the attitude of healthcare professionals who are at the frontline of identifying potential donors: limited local data ${ }^{[30]}$ and the experience among healthcare workers elsewhere suggest that they are less likely than the general public to donate their organs or those of their relatives after death, despite their knowledge of processes and the desperate need for organs. ${ }^{[31,32]}$ Educational programmes to change the attitudes of healthcare workers should be initiated early in their careers. ${ }^{[30,33]}$ A recent report identified nurses as healthcare workers who should be empowered to play a much greater role in the identification and referral of donors in SA. ${ }^{[34]}$

Table 2. Summary of possible strategies for increasing organ donation and transplantation in a developing country such as South Africa (see text for detail)

\begin{tabular}{ll}
\hline Intervention & Actions \\
\hline Encourage government involvement & Promote organ donation \\
- Reprioritise organ transplantation \\
- Promulgate relevant legislation \\
- Ensure fair organ allocation (audit) \\
- National registry of organ transplants and outcomes \\
- Promote dialogue in civil society \\
- Increase facilities to care for brain-dead donors \\
- Dedicated theatre time \\
- Enlarge the skills pool (surgeons, transplant co-ordinators) \\
- Extend transplant co-ordinators responsibilities across public-private platform \\
- Use marginal donors including non-heart-beating and HIV-infected donors \\
- Empower nursing professionals to refer \\
- Public education using various mechanisms to increase consent for donation \\
- Promote organ donation among healthcare professionals to improve referrals \\
- Policymakers informed and aware of the challenges \\
Changing attitudes & Donor prioritised in organ allocation if needed \\
- Consider rewarded gifting under state control
\end{tabular}


SA is emerging from a historically unequal past, and the discordant transplant rates between the private sector (which generally serves the minority insured population and those able to pay for the services provided by the sector) and the public sector (serving the majority poor and uninsured members of our society ${ }^{[10]}$ is alarming: the transplant rate in the insured is over three times that in the uninsured and compares favourably with that of high-income countries. ${ }^{[35]}$ This level of inequality between insured and uninsured patients is not unique: in Mexico the respective kidney transplant rates were 72 pmp in the insured compared with 7.5 pmp among the poor. ${ }^{[36]}$ In the USA, transplant rates among African Americans who are waitlisted are considerably lower than among whites, for a variety of medical and sociological reasons. ${ }^{[37]}$ In response to declining deceased donor numbers, the private sector in SA has successfully increased living donation, but in the public sector, living donations continue to decline. The reasons are the resource factors alluded to earlier and the fact that the public sector hospitals mainly serve uninsured patients, who tend to be poorer and less educated than those with medical insurance and have fewer social support structures. A potential donor may be a sole breadwinner who cannot risk his or her health or afford to take time off from work. ${ }^{[9]}$

The other disparity is the urban-rural divide. SA is a middleincome country and consists of nine provinces. Gauteng and the Western Cape - highly urbanised provinces - are the economic powerhouses of SA, commanding almost one-half of the country's gross domestic product, while the remaining provinces are largely rural. Hospitals in Gauteng and the Western Cape perform threequarters of all the transplants between them; Cape Town (Western Cape) also serves the Eastern Cape for kidney transplantation, Johannesburg (Gauteng) serves Limpopo and North West, Pretoria serves Mpumalanga (with some assistance from Johannesburg) and Bloemfontein serves the Northern Cape. The population of all nine provinces therefore has access to kidney transplantation. Of concern is the very low transplant rate in KwaZulu-Natal, which has SA's second-largest population and a robust economy; also, the number of transplants in the private sector in this province is double that in the public sector. The reasons for these inequities warrant further investigation.

The inequities in transplantation in SA - specifically the differences in transplant rates between the insured and the uninsured, and the urban-rural discrepancies - are an indictment on distributive justice in the country. The current allocation systems need to be reviewed and the inequities urgently addressed. A fair, transparent, audited allocation system that is open to public scrutiny is essential and must be coupled with the necessary accountability. The national government needs to take responsibility for the process and must ensure that results are formally reported and data, including outcomes, audited.

\section{Study limitations}

This study was limited by the quality and range of data collected and supplied by the Organ Donor Foundation. The detail captured increased marginally over the years and no outcome data were included. The data were not independently audited and their completeness and accuracy were therefore not fully verified. The data comprised all transplants including those in foreign nationals, but although these were not identified as such in the available information, they are unlikely to have significantly affected the transplant rate. However, the Organ Donor Foundation information is the only data currently available on transplantation in the country, and this is perhaps a clarion call for the SA transplant community to formalise the important process of data collection. This study focused on very specific aspects of kidney transplantation in SA, and the author acknowledges that there are many aspects and nuances that could not be addressed but should be considered for future investigation should more data become available.

\section{Conclusions}

This a comprehensive report on the overall state of kidney transplantation in SA. Critical issues are highlighted that should alert clinicians and policymakers to the challenges in kidney transplantation in the country, and this report should serve as a catalyst to interrogate current policies and seek ways of increasing access to transplantation in a fair and equitable way.

Declaration. None.

Acknowledgements. I am grateful to the Organ Donor Foundation for permitting access to their data, and to Profs Sarala Naicker and Tony Meyers and Drs Johan Nel and Yazied Chothia for their critical review of the manuscript.

Author contributions. Sole author.

Funding. None.

Conflicts of interest. None.

1. Fabian J, Maher H, Bentley A, et al. Favourable outcomes for the first 10 years of kidney and pancrea transplantation at Wits Donald Gordon Medical Centre, Johannesburg, South Africa. S Afr Med J 2016;106(2):172-176. https://doi.org/10.7196/SAMJ.2016.v106i2.10190

2. Barnard CN. The operation. A human cardiac transplant: An interim report of a successful operation performed at Groote Schuur Hospital, Cape Town. S Afr Med J 1967;41(48):1271-1274.

3. Delmonico FL, Domínguez-Gil B, Matesanz R, Noel L. A call for government accountability to achieve Delmonico FL, Domínguez-Gil B, Matesanz R, Noel L. A call for government accountability to achieve
national self-sufficiency in organ donation and transplantation. Lancet 2011;378(9800):1414-1418. national self-sufficiency in organ donation and
https://doi.org/10.1016/S0140-6736(11)61486-4

4. Davids MR, Marias N, Jacobs JC. South African Renal Registry Annual Report 2015. Afr J Nephrol 2017;20(1):201-213. https://doi.org/10.21804/20-1-2583

5. Mayosi BM, Lawn JE, van Niekerk A, Bradshaw D, Abdool Karim SS, Coovadia HM. Health in South Africa: Changes and challenges since 2009. Lancet 2012;380(9858):2029-2043. https://doi.org/10.1016/ S0140-6736(12)61814-5

6. Moosa MR, Kidd $M$. The dangers of rationing dialysis treatment: The dilemma facing a developing country. Kidney Int 2006;70(6):1107-1114. https://doi.org/10.1038/sj.ki.5001750

7. Moosa MR, Maree JD, Chirehwa MT, Benatar SR. Use of the 'Accountability for Reasonableness'
' approach to improve fairness in accessing dialysis in a middle-income country. PLoS One 2016;11(10):e0164201. https://doi.org/10.1371/journal.pone.0164201

8. Moosa MR, Meyers AM, Gottlich E, Naicker S. An effective approach to chronic kidney disease in South Africa. S Afr Med J 2016;106(2):156-159. https://doi.org/10.7196/SAMJ.2016.v106i2.9928

9. Muller E, Thomson D, McCurdie F. Transplantation in South Africa. Transplantation 2015;99(4):643645. https://doi.org/10.1097/TP.0000000000000712

10. Kevany S, Benatar SR, Fleischer T. Improving resource allocation decisions for health and HIV programmes in South Africa: Bioethical, cost-effectiveness and health diplomacy considerations. Glob programmes in South Africa: Bioethical, cost-effectiveness and health diplomacy
Public Health 2013;8(5):570-587. https://doi.org/10.1080/17441692.2013.790461

11. Muller E. Organ donation and transplantation in South Africa - an update. CME 2013;31(6):220-222.

12. World Health Organization. Global Status Report on Road Safety 2015. Geneva: WHO, 2015.

13. Scribante J, Bhagwanjee S. National audit of critical care resources in South Africa - transfer of critically ill patients. S Afr Med J 2007;97(12):1323-1326.

14. Mayosi BM, Benatar SR. Health and health care in South Africa - 20 years after Mandela. N Engl J Med 2014;371:1344-1353. https://doi.org/10.1056/NEJMsr1405012

15. Etheredge HR, Turner RE, Kahn D. Public attitudes to organ donation among a sample of urbandwelling South African adults: A 2012 study. Clin Transplant 2013;27(5):684-692. https://doi. org $/ 10.1111 /$ ctr.12200

16. Pike RE, Odell JA, Kahn D. Public attitudes to organ donation in South Africa. S Afr Med J 1993;83(2):91-94

17. Bass D. Kidneys for cash and egg safaris - can we allow 'transplant tourism' to flourish in South Africa? S Afr Med J 2005;95(1):42-44.

18. Jafar TH. Organ trafficking: Global solutions for a global problem. Am J Kidney Dis 2009;54(6):11451157. https://doi.org/10.1053/j.ajkd.2009.08.014

19. Comment. Organ trafficking and transplant tourism and commercialism: The Declaration of Istanbul. Lancet 2008;372(9632):5-6. https://doi.org/10.1016/S0140-6736(08)60967-8

20. Zivcic-Cosic S, Busic M, Zupan Z, et al. Development of the Croatian model of organ donation and Zivcic-Cosic S, Busic M, Zupan Z, et al. Development of the Croatian model of organ
transplantation. Croat Med J 2013;54(1):65-70. https://doi.org/10.3325/cmj.2013.54.65

21. Rudge C, Matesanz R, Delmonico FL, Chapman J. International practices of organ donation. Br J Anaesth 2012;108(Suppl 1):i48-i55. https://doi.org/10.1093/bja/aer399

22. Matesanz R, Miranda B. A decade of continuous improvement in cadaveric organ donation: The Spanish model. J Nephrol 2002;15(1):22-28.

23. South Africa. Department of Health White Paper. National Health Insurance Policy: Toward Universal Health Coverage. 2017.

24. Benatar S, Sullivan T, Brown A. Why equity in health and in access to health care are elusive: Insights from Canada and South Africa. Glob Public Health 2018;13(11):1533- 1557. https://doi.org/10.1080/ 17441692.2017.1407813

25. Simforoosh N. Kidney donation and rewarded gifting: An Iranian model. Nature Clin Pract Urol 2007;4(6):292-293. https://doi.org/10.1016/.j.transproceed.2006.01.012 
26. Delmonico FL. The alternative Iranian model of living renal transplantation. Kidney Int 2012;82(6):625-626. https://doi.org/10.1038/ki.2012.247

27. Lavee J, Ashkenazi T, Gurman G, Steinberg D. A new law for allocation of donor organs in Israel. Lancet 2010;375(9720):1131-1133. https://doi.org/10.1016/S0140-6736(09)61795-5

28. Lavee J, Ashkenazi T, Stoler A, Cohen J, Beyar R. Preliminary marked increase in the national organ donation rate in Israel following implementation of a new organ transplantation law. Am J Transplan 2013;13(3):780-785. https://doi.org/10.1111/ajt.12001

29. Thomson D. Organ donation in South Africa - a call to action. S Afr J Crit Care 2017;33(2):36-38 https://doi:10.7196/sajcc.2017.v33i2.352

30. Sobnach S, Borkum M, Hoffman R, et al. Medical students' knowledge about organ transplantation: A South African perspective. Transplant Proc 2010;42(9):3368-3371. https://doi.org/10.1016/ transproceed.2010.08.036

31. Hu D, Huang $\mathrm{H}$. Knowledge, attitudes, and willingness toward organ donation among health professionals in China. Transplantation 2015;99(7):1379-1385. https://doi.org/10.1097/ TP.000000000000079

32. Cohen J, Ami SB, Ashkenazi T, Singer P. Attitude of healthcare professionals to brain death: Influence on the organ donor process. Clin Transplant 2008;22(2):211-215. https://doi.org/10.1111/j.13990012.2007.00776.x
33. Hakeem AR, Dave R, Prasad KR, et al. An imperative need to change organ donation and transplant curriculum results of a nationwide United Kingdom junior doctor survey. Transplantation 2015:99(4):771-785, https://doi.org/10.1097/TP.0000000000000423

34. Crymble K, Fabian J, Etheredge H, Gaylard P. Perceptions of nurses' roles in end-of-life care and organ donation - imposition or obligation? S Afr J Med 2017;107(7):573-575. https://doi.org/10.7196/ SAMJ.2017.v107i7.1248

35. World Health Organization and Spanish Transplant Organization. Global Observatory on Donations and Transplantation. 2016. http://www.transplant-observatory.org/ (accessed 1 July 2018).

36. Garcia-Garcia G, Monteon-Ramos JF, Garcia-Bejarano H, et al. Renal replacement therapy among disadvantaged populations in Mexico: A report from the Jalisco Dialysis and Transplant Registry (REDTJAL). Kidney Int 2005;68(97):S58-S61. https://doi.org/10.1111/.j.1523-1755.2005.09710.x

37. Powe NR. To have and have not: Health and health care disparities in chronic kidney disease. Kidney Int 2003;64(2):763-772. https://doi.org/10.1046/j.1523-1755.2003.00138x

Accepted 29 August 2018. 